\title{
UN INTENTO, EN CLAVE CONSTITUCIONAL, POR INTERPRE- TAR UN POSIBLE FIN DE LA PENA
}

\author{
Hernán Darío Grbavac ${ }^{1}$
}

\section{Planteamiento del tema}

No voy a discurrir aquí sobre las diferentes teorías de la pena que desde tiempos inmemoriales se han esbozado. No incursionaré en un análisis pormenorizado sobre las diferentes construcciones teóricas elaboradas por distintos autores, con sus consecuentes virtudes y críticas. El objeto de este trabajo es otro. Solo busca tratar de hacer visible un problema en materia de interpretación sobre qué teoría de la pena recepta nuestra $\mathrm{CN}$ (si es que recepta una). Es una réplica a la argumentación, que por otra parte cuenta con cierta estabilidad, que afirma que nuestra Carta Magna, con la reforma de 1994, ha adoptado la prevención especial positiva como la finalidad que gobierna la pena. Discutir esta conclusión muchas veces equivale a una herejía. Sin embargo, intentaré demostrar que aquella aseveración no está tan exenta de dudas como se expresa; que ella no es "neutral”, entendido ello como conclusión de un razonamiento lógico, por el contrario, implica un presupuesto valorativo encubierto. Finalmente expondré mi conclusión sobre cuál podría ser (si es que hay uno) el fin de la pena para nuestro ordenamiento jurídico.

\section{La Constitución Nacional antes de la reforma de 1994}

Desde la sanción de la CN en 1853-60, se interpretó que el núcleo central de las garantías constitucionales que pertenecen a cada individuo, así como también el tratamiento dispensado a la cuestión penal, se encontraban reglados en los Artículos 18 y 19. Para el tema que nos ocupa, el Artículo 18 expresa que: "Las cárceles de la Nación serán sanas y limpias, para seguridad y no para castigo de los reos detenidos en ellos”. Esta disposición es la única referencia a las prisiones. Este artículo a lo largo de su contenido, se refiere a

${ }^{1}$ Profesor Derecho Penal II y Práctica Profesional IV (UCP); colaborador Derecho Penal I y II (UNNE). 
la pena, al decir que nadie "puede ser penado sin juicio previo fundado en ley anterior al hecho del proceso" (primera parte). Y más adelante: “Quedan abolidos para siempre la pena de muerte por razones políticas, toda especie de tormentos y los azotes”. ${ }^{2}$ Luego, no hay ningún artículo que contenga alguna referencia a la finalidad o sentido de la pena de prisión, que es la sanción penal por excelencia.

Ante la presunta indeterminación del constituyente sobre el fin de la pena, cada autor se lanzó a justificar por qué la pena debía tener un fin determinado y no otro. Así Núñez, ${ }^{3}$ luego de rechazar el retribucionismo, decía que se castiga para que no se delinca, lo que puede lograrse con la readaptación social del reo (fin individual de la pena), como así también funcionando como prevención para los demás miembros de la sociedad (fin general de la pena). En tanto Soler ${ }^{4}$ expresaba que la pena tiene diferentes fundamentos, de acuerdo con los diferentes momentos que se analicen. ${ }^{5}$ En un primer momento, y desde un punto de vista social, tiene como fin la prevención general. Cuando el delito se comete, la sanción se aplica por lo que se hizo (retribución), pero siempre buscando evitar que el autor (prevención especial) o terceros (prevención general) cometan delitos en el futuro.

${ }^{2}$ Hay otros artículos de la CN que también recuerdan a la pena, aunque ninguno de ellos refiere a una finalidad expresa de aquélla. Así, p. ej., el art. 23, cuando regula el estado de sitio, prohíbe al presidente condenar "ni aplicar penas"; el art. 29, que fija la pena de infames traidores a la patria; el actual art. 69, que refiere a un legislador sorprendido in fraganti en la ejecución de un delito; actual art. $995^{\circ}$ que faculta -bajo ciertas circunstancias- al presidente a indultar o conmutar penas por delitos sujetos a jurisdicción federal.

${ }^{3}$ Núñez, Ricardo C. (1975), Manual de Derecho Penal. Parte General (2a edic.), Lerner, Córdoba, págs. 320-321; Derecho Penal Argentino (1960), T II, págs. 348-349 Bibliográfica Omeba, Buenos Aires, donde se cita en apoyo del fin de prevención especial positiva la entonces vigente ley penitenciaria nacional, complementaria del CP, ratificada por Ley 14467, art. 1: la ejecución de las penas privativas de libertad tiene por objeto la readaptación social del condenado.

${ }^{4}$ Soler, Sebastián (1963), Derecho Penal Argentino, T II (3 ${ }^{\text {a }}$ edic.), Tea, Buenos Aires, págs. 344-360.

${ }^{5}$ Obsérvese como la tesis de soler guarda mucha similitud con la "Teoría de la Unión” de Roxin, que considera que la pena tiene y persigue ciertas finalidades diferentes que no se excluyen. Ver Roxin, Claus (1997), Derecho Penal. Parte General, T. I. Trad. de la $2^{\mathrm{a}}$ edic. alemana y notas por Diego M. Luzón Peña, Miguel Díaz,. García Conlledo y Javier De Vicente Remesal, Civitas, Madrid, págs. 95-103. 
En otras palabras, parecería que la CN histórica de 1853-60 delegó ${ }^{6}$ en el legislador o en el juez el determinar el fin de la pena. Ahora bien, la presunta indeterminación constitucional, pareció llegar a su término, cuando la reforma de 1994 incorporó al ordenamiento jurídico argentino, con jerarquía constitucional, una serie de tratados de Derechos Humanos, que receptarían expresamente una finalidad determinada para la sanción penal.

\section{La reforma de 1994. La incorporación de tratados internacionales de Derechos Humanos con jerarquía constitucional}

Con la reforma de 1994 adquirieron jerarquía constitucional en el derecho argentino una serie de Tratados Internacionales de Derechos Humanos, que ya habían sido previamente receptados como ley nacional por el Poder Legislativo. Entre estos instrumentos, existen algunos que se expresan ratificando diría- textualmente lo preceptuado por el art. $18 \mathrm{CN}$, y otros, que habrían incorporado o se refieren a la prevención especial positiva como el fin de la pena. Entre los primeros, la Declaración Americana de los Derechos y Deberes del Hombre (DADDH) en su art. XXVI expresa que toda persona tiene derecho a que no se le impongan penas, crueles, infamantes o inusitadas. En igual sentido la Declaración Universal de Derechos Humanos (DUDH), en su art. 5, prohíbe la aplicación de torturas, penas o tratos crueles, inhumanos o degradantes. También se encuentran disposiciones similares en la Convención Americana de Derechos Humanos (CADH), art. 5. 2: "Nadie debe ser sometido a torturas ni a penas o tratos crueles, inhumanos o degradantes. Toda persona privada de libertad será tratada con el respeto debido a la dignidad inherente al ser humano"; art. 5. 4: "Los procesados deben estar separados de los condenados, salvo en circunstancias excepcionales y serán sometidos a un tratamiento adecuado a su condición de personas no condenadas"; art. 5. 5: "Cuando los menores puedan ser procesados, deben ser separados de los adultos y llevados ante tribunales especializados, con la mayor celeridad posible, para su tratamiento”. En el Pacto Internacional de Dere-

${ }^{6}$ Véase una exposición de la teoría de la delegación como teoría interpretativa, como así también de otras teorías, en Dworkin, Ronald (2012), El foro de los principios en una cuestión de principios, trad. de Victoria Boschiroli. Siglo XXI, Buenos Aires. 
chos Civiles y Políticos (PIDCP), art. 7: "Nadie será sometido a torturas ni a penas o tratos crueles, inhumanos o degradantes”; art. 10. 1: “Toda persona privada de su libertad será tratada humanamente y con el respeto debido a la dignidad inherente al ser humano"; art. 10. 2 a.: "Los procesados estarán separados de los condenados, salvo en circunstancias excepcionales, y serán sometidos a un tratamiento distinto, adecuado a su condición de personas no condenadas".

Entre los segundos, la propia CADH y el citado PIDCP hacen mención expresa a la readaptación o resocialización del condenado, amén de prohibir la primera la aplicación de la pena de muerte en aquellos Estados que hayan abolido esta sanción (art. 4. 3) lo que puede interpretarse como una consecuencia de la búsqueda de la reinserción del reo. Dice la CADH: "Ias penas privativas de libertad tendrán como finalidad esencial la reforma y la readaptación social de los condenados” (art. 5. 6). En tanto el PIDCP reza en su art. 10. 2 c.:

el régimen penitenciario consistirá en un tratamiento cuya finalidad esencial será la reforma y la readaptación social de los penados. Los menores delincuentes estarán separados de los adultos y serán sometidos a un tratamiento adecuado a su edad y condición jurídica

Y en el art.14. 4: "En el procedimiento aplicable a los menores de edad a efectos penales se tendrá en cuenta esta circunstancia y la importancia de estimular su readaptación social”. A su vez, y como derivación lógica de los tratados citados, la ley 24660, de ejecución de la pena privativa de la libertad, en su artículo $1^{\circ}$ deja sentado que la citada ejecución "en todas sus modalidades, tiene por finalidad lograr que el condenado adquiera la capacidad de comprender y respetar la ley procurando su adecuada reinserción social, promoviendo la comprensión y el apoyo de la sociedad”, debiéndose adoptar todos los medios a los fines de lograr la finalidad apuntada.

Lo expuesto parecería afirmar que no hay ya margen alguno de discusión posible, que la $\mathrm{CN}$ ha adoptado la prevención especial positiva como el fin de la pena, y que toda opinión en contrario no haría sino contradecir el texto constitucional. Más aún, como dicha tesis se aloja en dos tratados internacionales, su perdurabilidad estaría asegurada, en el sentido de que el Estado argentino debería denunciar tales instrumentos internacionales si prefiriese el día de mañana abrazar otra teoría de la pena. Ahora bien ¿Es ello realmente así? ¿El conte- 
nido de aquella conclusión es tan evidente que no puede discutirse? En el apartado que sigue trataré de argumentar que la veracidad en el contenido de aquélla es falsa. Basta ahora citar a Zaffaroni, que por otros motivos, también rechaza la idea de la prevención especial positiva como fin recogido por la CN.

Como es sabido, este autor adopta una teoría negativa o agnóstica de la pena, ${ }^{7}$ de manera que debe replicar aquel argumento prevencionista a los fines de sostener su visión del sistema penal. Así dice ${ }^{8}$ que aquel razonamiento es meramente exegético, y que sería válido si el derecho penal fuera una mera exégesis de la ley penal prescindiendo de la realidad y de las consecuencias sociales de su práctica. Así a partir de su teoría negativa contesta que pueden adoptarse alguna de las siguientes hipótesis: a) el art $18 \mathrm{CN}$ solo se refiere a la seguridad de los detenidos, además de que incluye también a quienes aún no fueron condenados -lo que implicaría tratar de resocializar a quienes tal vez no estén desocializados-; b) la CADH asume un postulado imposible por el estado estructural de las prisiones, debiendo interpretarse sus cláusulas en un sentido progresivo, esto es, como lo más cercano a aquel horizonte; c) la inconstitucionalidad del concepto de peligrosidad de la ley penal que permitiría el foco sobre ciertos sujetos peligrosos, que como tales deben ser resocializados.

Sin embargo, creo que la tesis de Zaffaroni no termina por dilucidar la cuestión. En primer término por su referencia a una supuesta realidad, entendida como presupuesto ontológico que no podría ser desconocida por el sujeto, so pena de incurrir en un absurdo. Esta teoría es autoritaria y dogmática, puesto que impide discutir la citada "realidad objetiva", debiendo respetarse aquella conclusión efectuada sin fundamento por quien tiene el poder fáctico de definirla. En segundo lugar, el razonamiento parece estar dirigido a ingresar en los postulados conceptuales de la teoría de quien lo afirma. Esto es claro en su referencia a las cláusulas de la $\mathrm{CADH}$, lo que se complementa con la crítica anterior efectuada. Así el razonamiento de Zaffaroni diría aproximadamente: "como sostener la resocialización implica desconocer la realidad-crítica primera-, los artículos deben ser interpretados en este otro sentido, que

${ }^{7}$ Ver p. ej., Zaffaroni, Eugenio R.; Alagia, Alejandro \& Slokar, Alejandro (2005), Derecho Penal. Parte General (2 $2^{\mathrm{a}}$ edic.), Ediar, Buenos Aires; Manual de Derecho Penal. Parte General ( $2^{\mathrm{a}}$ edic.), Ediar, Buenos Aires.

${ }^{8}$ Zaffaroni, Eugenio R.; Alagia, Alejandro \& Slokar, Alejandro, ob. cit., pág. 55. 
concuerda con mi teoría -segunda crítica-”, lo que además trae el peligro de rescribir las cláusulas de la CADH. Y en tercer lugar, esta tesis tiene la sorprendente característica de "aceptar" o conceder cierta plausibilidad a la conclusión que critica. De otro modo, como comienza aceptando que el texto acepta ese fin de prevención especial, acude luego a argumentos ónticos, estructurales, etc., para rechazar aquella conclusión. Esto se observa cuando alude que la tesis de la mayoría es exegética -puramente literal-, y que sería cierta si no es que las prisiones en la realidad, etc. Esta es otra diferencia -como se verá más adelante- con el enfoque que se propugna en este escrito.

Sin embargo la tesis de Zaffaroni tiene los siguientes méritos. En primer lugar, discute una supuesta verdad revelada -el fin de prevención especial positiva-, aunque en el fondo -como se dijo- su argumentación pierde fuerza por la concesión indicada a la misma. En segundo término, no interpreta aisladamente el contenido de las cláusulas que nadie discute.

Seguidamente trataré de exponer las razones que me llevan a cuestionar el postulado de prevención especial positiva como fin de la pena seguido por el texto constitucional, procurando evitar incurrir en las críticas marcadas a Zaffaroni. Finalmente se expondrá una conclusión constructiva sobre si es posible determinar si la pena tiene un fin según la CN.

\section{La tesis que se propugna}

Como se ha dicho, considero falso el contenido de la afirmación de que la $\mathrm{CN}$ ha abrazado a la prevención especial positiva como fin de la pena. En primer lugar sostener que la Constitución con la reforma de 1994 adoptó ese fin de la pena, implica afirmar uno de los siguientes dos extremos: a) que la CN de 185360 delegó en otros órganos la decisión de cuál es el fin de la pena-lo que parecería que sostenían Núñez y Soler, p. ej.- ; o b) que la CN de 1853-60 a través de su art. 18 de manera implícita recogía a la prevención especial positiva.

Ambas conclusiones derivan de que los tratados internacionales con jerarquía constitucional, no pueden ser interpretados como negación del contenido de la primer parte de la CN -llamada también parte dogmática-, sino que al contrario, deben ser entendidos como complementarios de los derechos y garantías por ella reconocidos. Y ello no solamente porque el propio art. 75 inc. 22 segundo párrafo $\mathrm{CN}$ así lo dice expresamente, sino porque sostener lo contrario implica afirmar que la $\mathrm{CN}$ en su primera parte fue reformada (por los citados 
tratados) sin que la ley que declaró la necesidad de la reforma haya introducido dichas cláusulas entre aquéllas que la Convención Constituyente podía modificar (lo que viciaría de nulidad absoluta ${ }^{9}$ a la reforma en este punto). Por otro lado, la incorporación de los tratados con la citada jerarquía, y la frase expresa contenida en el propio art. 75 inc. 22 responden a la ideología política y filosófica adoptada por la $\mathrm{CN}$ de respeto y reconocimiento a los derechos individuales básicos del hombre, ante las ilegítimas intromisiones del Estado y de terceros recuérdese que fueron elevados de categoría legal a constitucional-. En otras palabras los tratados solo actúan como un plus respecto a lo consagrado en la primer parte de la Constitución (denominada también "Declaraciones, Derechos y Garantías”).

Sentado lo expuesto cabe ahora preguntarse si la ideología política liberal de la CN es indiferente a cualquier teoría de la pena que se adopte. Si la respuesta a esta cuestión es negativa, el primero de los extremos anteriormente citados sería equivocado.

Creo que la respuesta debe ser necesariamente negativa. Una teoría de la pena no es un razonamiento meramente académico o teórico desprovisto de consecuencias prácticas para los derechos de los individuos. Implica además una toma de postura filosófica sobre el hombre, la autoridad del Estado para aplicar la sanción, los límites de esta, su justificación, etc. Dicho de otro modo la teoría de la pena que se adopte implica asumir un compromiso de carácter filosófico-político sobre la organización de la sociedad y el Estado. En el ámbito del Derecho Penal, p. ej., trae consecuencias para la aplicación o no de una sanción, cometido un delito. La CN al abrazar al liberalismo político adoptó una serie de postulados incompatibles con ciertos fines de la pena. En primer lugar, es opuesta -sin necesidad de mayores explicaciones- con la prevención especial negativa, adepta a la mutilación física. Pero también se pronunció en contra del retribucionismo, toda vez que este es compatible con postulados perfeccionistas, que como tales establecen que la legislación debe perseguir como objetivo que los hombres sean "más perfectibles". El perfeccionismo dispone que las leyes no sancionen la violación de derechos ajenos, sino ciertos vicios o actitudes que degradan o per-

${ }^{9}$ Que, por otra parte, fue la conclusión de la CSJN en "Fayt, Carlos Santiago c/ estado nacional s/ proceso de conocimiento”, sobre la cláusula -impugnada por el propio juez Faytreferida a la edad de 75 años hasta la que sin designación posterior permanecerían los jueces federales en sus funciones (CN, art. 99 inc. $\left.4^{\circ}\right)$. 
judican al propio sujeto que realizó la acción. Ello lleva que en materia penal, p. ej., se relegue la afectación de derechos ajenos como núcleo para la intervención del Estado (lo que violaría el art. $19 \mathrm{CN}$ ), priorizando el aspecto subjetivo del agente, lo que por otra parte guarda relación con la idea de reproche. Este es el problema central del retribucionismo,$^{10}$ que acentúa su mirada en el aspecto subjetivo del sujeto con prescindencia de la faz externa de la conducta, lo que a su vez, reforzado por la idea de reproche necesariamente remite a parámetros morales sobre lo que está bien o mal, independientemente de la dimensión intersubjetiva del hecho en cuestión.

Por otra parte el enfoque agnóstico propuesto por Zaffaroni tiene el inconveniente de no distinguir la aplicación de una pena por parte de un órgano democrático y republicano, que de un órgano dictatorial, ni la distinción entre la actuación de aquél y un sujeto particular que infringe la ley. Al fin y al cabo qué diferencia habría entre el sujeto que secuestra y el juez que condena a una pena de prisión al imputado. Ello creo que obscurece la cuestión, con merma de la función, en los límites de su actuación, de los órganos que la CN -hija de un amplio consenso- establece que desarrollen. Finalmente es una salida facilista que no resuelve ni propone nada plausible, puesto que no parece que la sociedad hoy quiera -ni sea deseable- o pueda prescindir de la pena de prisión.

Queda ahora por analizar las restantes vertientes prevencionistas. Todas ellas, aplicadas sin ningún tipo de correctivo, tienen el problema utilitarista de usar al hombre como un medio para mayores beneficios -lo que lesiona el principio de inviolabilidad de las persona que reza que las personas son fines en sí mismas y nunca medios-. Sin embargo, amén de ello, considero que la CN no observa la prevención general positiva, toda vez que esta valora a la pena como un bien que se aplica para validar la vigencia de la norma, lo que al ampliar la punición -ella sería loable- restringe la libertad individual al tiempo que oscurece los criterios que deben regir la criminalización de hechos (relegando la vigencia del art. $19 \mathrm{CN}$ ).

Como se dijo más arriba, tampoco soy partidario -ni creo que la CN la haya adoptado- de la prevención especial positiva. Ahora bien ¿Por qué soy

${ }^{10}$ Ver las siguientes obras, donde se exponen críticas al retribucionismo: Moccia, Sergio (2008), El derecho penal entre ser y valor. Función de la pena y sistemática teleológica, trad. de Antonio Bonanno, cap. II y IV, B de F, Buenos Aires; Nino, Carlos S. (2006), Los límites de la responsabilidad penal. Una teoría liberal del delito, cap. III y IV, Astrea, Buenos Aires. 
contrario a ella? Porque si el objetivo es la resocialización, ello lleva a que el Estado se erija casi en guardián moral de las conductas de los ciudadanos lo que le está vedado por el art. $19 \mathrm{CN}$-que no recoge sino el principio antiperfeccionista en materia de legislación-. La resocialización, igual que el retribucionismo, enfatiza las actitudes subjetivas del sujeto, lo que la hace prescindir del daño externo de la acción desplegada, con la agravante de que lo hace para "curar", lo que lleva a introducir, al proceso penal, postulados médicos recuérdese aquí a Lombrosso. Así la cenicienta pasa a ser el combate a ciertos vicios peligrosos de ciertos sujetos, lo que ayudó a forjar la idea de “individuos peligrosos” a finales del S XIX. De otro modo, la prevención especial positiva, es hija del positivismo penal -p. ej., era la teoría que seguía von Liszt-. Por otra parte, también permite ampliar la punición, guiado por fines nobles como serían la curación y mejora del sujeto. Que el condenado no se queje ni se preocupe puesto que la pena que se le aplica es por su bien, lo que tal vez no puede comprender por qué no está socializado. Esto era alertado ya por Soler, cuando decía ${ }^{11}$ que ciertos positivistas al sostener el fin de prevención especial positiva descuidaban el carácter de mal que tiene la pena. Así no parece que una $\mathrm{CN}$ políticamente liberal haya seguido un criterio rector antiliberal para penar. Por otro lado, es interesante el argumento de Zaffaroni que el art. 18 no se refiere solo a condenados. Pero independientemente de ello, dicha norma -considero- sienta un criterio en materia de aplicación concreta de la pena, un principio humanista, de respeto absoluto a la condición humana. Consecuentemente con ello las cláusulas internacionales citadas -que se complementan con el art. 18- se refieren a la ejecución misma de la pena de prisión, no al criterio que debe observarse para aplicar una pena. Es decir, se refiere a una pena ya aplicada, no a la máxima que debe buscarse para aplicar una pena al momento de dictar una sentencia o de erigir una conducta en delito. Incluso la ley 24660, que hace mención expresa a la readaptación social, reafirma esta conclusión si se tiene en cuenta que es la norma que regula la ejecución de la pena privativa de la libertad. También el PIDC remite al régimen penitenciario cuando expresa la idea de readaptación y reforma de los condenados. Es notable que el propio Zaffaroni -como se dijo- apele a criterios de interpretación progresiva, al analizar esta cuestión, lo que implica afirmar que no es contradic-

${ }^{11}$ En Derecho Penal... T II, págs. 346 y 352. 
torio para él, en principio, sostener la prevención especial positiva como fin "abstracto" de la pena.

La posición mayoritaria, que aquí se critica, omite tratar estas objeciones acudiendo para ello a un criterio presuntamente neutral. Ello no es nuevo en la actuación de la dogmática penal, ${ }^{12}$ cuya función verdadera en la práctica es facilitarle el trabajo al juez para condenar. El razonamiento parte de una supuesta afirmación expresa de la norma -que como se vio no es tal, puesto que puede interpretarse como referida a la etapa de ejecución-, para sostener a partir de ello una conclusión en apariencia valorativamente neutral. Sin embargo, la citada neutralidad no existe. Obsérvese además cómo el razonamiento apuntado se demuestra absurdo, puesto que debería llevar a concluir que los códigos procesales penales, que eliminaron la institución del procesamiento, incurrieron en una inconstitucionalidad, toda vez que p. ej., la CADH (art. 5. 4.) menciona que los procesados deben estar separados de los condenados; o el art. 5. 5: "cuando los menores puedan ser procesados".

El ordenamiento jurídico se termina fundando en última instancia en pautas de moralidad social. ${ }^{13}$ Ello lleva a que se deba preguntar entonces cómo se resuelve este tema, es decir, qué criterios o parámetros se deben tomar en cuenta para determinar cuál sería una posible finalidad de la pena, seguida por la CN toda vez que su texto (art. 18 y los tratados internacionales) hace referencia a ese instrumento de sanción.

Como se habrá advertido no me he referido a la prevención general negativa como fin de la pena. Considero que esta teoría, depurada de los errores utilitaristas apuntados, tiene una serie de ventajas: $1^{\circ}$ ) considera a la pena como un mal, cuando sostiene que aquélla actúa psíquicamente como una suerte de amenaza, de coacción en potencia, para que no se cometan delitos. Consecuentemente se refiere a uno de los dos aspectos centrales que Carlos Nino recordaba ${ }^{14}$ que cualificaban a la pena: consistir en un sufrimiento para el condenado (amén de ser un estigma para él -segunda característica-); $2^{\circ}$ ) Se compatibiliza con el núcleo central de la idea de sanción propia de todo el derecho -la amenaza de un sufrir un mal, lo que hace que la mayoría de los individuos actúen conforme a derecho, amén de sus principios morales-. Un líder

\footnotetext{
${ }^{12}$ Ver Nino, Carlos S., los límites..., ob. cit.

${ }^{13}$ Véase p. ej., Nino, Carlos S. (2012), La validez del derecho, Astrea, Buenos Aires.

${ }^{14}$ En Nino, Carlos S., los límites..., ob. cit.
} 
político decía con sabiduría: “los hombres son buenos pero son mejores si se los controla"; $3^{\circ}$ ) al aplicar en concreto una pena, esta no dirige su mirada al imputado aisladamente, sino a la sociedad, esto es, se aplica una sanción para disminuir los males -entre los que debe contarse la propia suerte del condenado, en tanto parte de la sociedad- que existirían de no aplicarse aquella; $4^{\circ}$ ) al adoptar un postulado general, al tener en vista a la sociedad, es compatible con el monopolio de hecho que ejerce el Ministerio Público en la investigación de los delitos y, eventualmente, en la búsqueda de sanción; $5^{\circ}$ ) el punto $4^{\circ}$ es compatible además con la obligación del Estado de brindar seguridad a sus ciudadanos. Es decir, tomar la idea de pena y su finalidad de la actividad del Ministerio Público permite diagramar un sistema racional de persecución de los delitos en base a pautas claras y en búsqueda de objetivos concretos. Estos estarán seguramente gobernados por la idea de lograr el mayor bienestar general, debiendo respetarse necesariamente los derechos del imputado -de lo contrario se los estaría usando como un medio, lo que violaría el imperativo kantiano-. Esta era, por otra parte, la idea que caracterizaba la pena en la teoría de Carlos Nino en Los límites de la responsabilidad penal.

$\mathrm{Al}$ criticar las posturas anteriores, si se observa, he acudido a ciertos principios a los efectos de rechazar la versión mayoritaria que afirma la CN ha adoptado la prevención especial positiva como fin de la pena. Sin embargo no se hizo referencia a la siguiente circunstancia. Cuento -además- con el articulado expreso de la CN para sostener la crítica que he esbozado y fundar una posición constructiva alrededor de una "prevención general negativa filtrada". En otras palabras, no es cierto que el texto constitucional solamente contenga una referencia a la pena en las cláusulas internacionales que se han citado. La propia CN y no a través de los tratados- también puede ofrecer una teoría sobre la pena. Se trata del art. 120 CN que regula la institución del Ministerio Público. Esta interpretación, hasta lo que tengo conocimiento, es inédita. Ningún constitucionalista o penalista, ni ningún manual de Derecho Constitucional o de Derecho Penal estructuran una visión o teoría de la pena a partir de este artículo. Seguidamente trataré de mostrar por qué considero que esta norma contiene datos sobre el tema, ratificados -a nuestro juicio- en base a los principios que nos permitieron criticar las tesis anteriores -entre ellas la mayoritaria-.

El art. 120 primer párrafo CN dice: "El Ministerio Público es un órgano (...) que tiene por función promover la actuación de la justicia en defensa de la legalidad, de los intereses generales de la sociedad, en coordinación con las demás autoridades de la República”. En este artículo la CN 
reconoce y organiza al Ministerio Público. Este es el órgano por excelencia para promover la acusación de quienes pudieron haber cometido delitos. Se integra, en este aspecto, con fiscales, quienes promueven la actuación de la justicia -órgano imparcial que decide la controversia entre las partes-. En un proceso penal, un fiscal puede solicitar o no la condena de un imputado, de acuerdo con lo que haya sucedido o no respecto del hecho objeto del juicio. Si requiere una condena, o sea si solicita la aplicación de una pena, lo hace-según la letra del propio art. 120- en defensa de la legalidad y de los intereses generales de la sociedad ¿Qué quiere decir ello? ¿Cómo deben interpretarse tales palabras? Creemos que una interpretación plausible puede ser la siguiente. El fiscal al pedir una pena lo debe hacer: a) en cumplimiento estricto de la ley -en defensa de la legalidad-, puesto que no solo no es un acusador nato, sino que además sería intolerable que el propio Estado (a través de uno de sus órganos) se valiera de violaciones a la legalidad en su actuación. Perdería así toda legitimación moral para solicitar una condena a quienes también infringieron la ley, y b) realiza esa solicitud en defensa de la sociedad -defensa de los intereses generales de la sociedad-. Es decir, el art. 120 recepta una hipótesis de prevención general, -toda vez que dirige su mirada hacia la sociedad-, y negativa -dado que no refiere a la defensa de la norma ni del sistema, sino de los ciudadanos, que se sentirían atemorizados ${ }^{15}$ por la existencia de sujetos que deberían estar condenados y no lo están-. Ese temor se cancela, se borra, con la aplicación de la condena pertinente. Pero en ese cálculo "utilitarista" a efectuar por el fiscal deben computarse los intereses del propio condenado -que es parte de la sociedad-. Vale la pena aquí citar las siguientes palabras de Nino, quien interpretaba a la pena como un supuesto de estado de necesidad justificante cometido por el Estado. Decía que la protección social, solo puede efectuarse a través de aquella, cuando se presenten una serie de

consideraciones puramente racionales de prudencia. Estas consideraciones son, en general, las mismas que casi todos los sistemas jurídicos toman en cuenta para caracterizar el estado de necesidad justificante: a) debe haber la certeza o una gran probabilidad de

${ }^{15}$ Ello era constitutivo para carrara -quien fue uno de los expositores más ilustres de un sistema liberal- del "daño mediato" que produce un delito. Ver Carrara, Francesco (2010), Programa del curso de derecho criminal dictado en la real universidad de pisa. Parte General, Vol. I, trad. de la $11^{\mathrm{a}}$ ed. italiana dirigida por Sebastián Soler, con la colaboración de Ernesto Gavier y Ricardo Núñez. El foro, Buenos Aires. 
que lo que se considera un mal va a ocurrir; b) la medida protectora debe ser la a la vez necesaria y efectiva para prevenir ese mal; c) tal medida debe implicar un mal menor que el que ella tiende a precaver. ${ }^{16}$

Obsérvese que la interpretación formulada parte del texto del art. 120, intenta ser fiel al mismo y, por otro, lado guarda coherencia con el sistema político liberal propugnado por la $\mathrm{CN}$, que es el que impide-sin perjuicio del art. 120 - adoptar alguna de las otras finalidades expuestas para la pena.

Se me podrá criticar diciendo que apelo, con la referencia al sistema político liberal, a una supuesta intención del constituyente, que además de ser difusa no la he probado. No obstante, creo que la crítica no es fundada. También considero que la llamada intención del legislador no existe, si entendemos por tal lo que comprendemos cuando hacemos referencia a los objetivos que tuvo una persona física al hacer tal cosa o cuáles fueron sus finalidades.

Sostengo, por el contrario, que ese recurso argumentativo debe ser pulido para ser reconducido a otros cauces. No creo que pueda comprobarse -si es que existe- la intención “real”, concreta de un sujeto al crear una norma. Más aún, tal circunstancia se ve agravada si se tiene en cuenta que la llamada intención del legislador (o constituyente) debe abarcar los motivos de una persona jurídica (Congreso, Convención Constituyente), con lo que entender el término como sinónimo de lo que consideramos con relación a la actuación de una persona física, es un absurdo. Sin embargo, toda interpretación de una norma no es neutral o desprovista de valoraciones (hay una toma de postura entre lo que opina la posición mayoritaria y mi teoría). Ello es consecuencia muchas veces de la indeterminación del lenguaje.

Ahora bien, toda tarea de reconstrucción del significado de una norma debe partir de la letra de la ley y, cuando el lenguaje se muestre dudoso, ambiguo, vago, abierto, etc., deberá apelarse a la llamada “intención” del legislador que tiene otros contornos. Cuando se alude a la intención del legislador se lo hace en el sentido de "intención objetiva”, esto es, de aquellas valores o propiedades que el derecho quiere promover o prevenir -según el caso-, de acuerdo con ciertos ideales de filosofía política y de moralidad social, que se encuentran

${ }^{16}$ Nino, Carlos S., Los límites..., ob. cit., pág. 210. 
implícitos en el ordenamiento jurídico de que se trate -de alguna manera constituyen la red en la que se tejen las normas expresas-, y que solo se encuentran limitados por los derechos de las personas -lo que también es una toma de posición en materia de filosofía política-. Este pensamiento se remonta a las ideas de autores como Nino y Dworkin. El primero sostenía este sentido del término intención de legislador, cuando decía que dicho concepto "es una construcción lógica... (que) difiere totalmente del que considera que la intención del legislador es una especie de ficción”. ${ }^{17}$ En tanto Dworkin ${ }^{18}$ luego de negar la idea de intención como equivalente a la que tiene una persona física (pp. 60/ 61), enfatiza que esta cuestión se estructura a partir de una teoría política (pp. $63,74,81)$. La llamada por él “intención abstracta” no es sino la finalidad de lo que el orden jurídico a través de un órgano competente para ello (ej. Convención Constituyente) alienta. Toda decisión que se tome en materia de interpretación debe hacerse al servicio de tales juicios (pp. 71/73, 78/79). Finalmente expresa que los jueces deciden estos temas sobre la base de una moral política sustancial, que solo encuentra como barrera los derechos de las personas (pp. 95/96, 98 y 100), lo que se grafica en su famosa frase de que "los derechos son cartas de triunfo".

Obsérvese además que en este tema la cuestión parece ser facilitada por el texto expreso de la misma CADH que en su art. 29 expresa:

Normas de interpretación: Ninguna disposición de la presente convención puede ser interpretada en el sentido de: a) Permitir a alguno de los Estados Partes, grupo o persona, suprimir el goce y ejercicio de los derechos y libertades reconocidos en la convención o limitarlos en mayor medida que la prevista en ella; b) Limitar el goce y ejercicio de cualquier derecho o libertad que pueda estar reconocido de acuerdo con las leyes de cualquiera de los Estados Partes o de acuerdo con otra convención en que sea parte uno de dichos Estados; c) Excluir otros derechos y garantías que son inherentes al ser humano o que se derivan de la forma democrática representativa de gobierno, y d) Excluir o limitar el efecto que puedan producir la Declaración Americana de Deberes del Hombre y otros actos internacionales de la misma naturaleza.

${ }^{17}$ Nino, Carlos S., Los límites..., ob. cit., pág. 318, nota 32.

${ }^{18}$ Dworkin, Ronald, El foro..., ob. cit. 
Fíjese como las ideas sentadas en este trabajo guardan coherencia con el art. 29 citado, que en sus incisos a, b y c, establece como un límite a observar, los derechos y libertades de las que gozan los sujetos, sean los mismos reconocidos por la propia convención o por las leyes de cada Nación. Ello no es sino consecuencia del cumplimiento del principio de igualdad, como así también del sistema político democrático de gobierno. Por otra parte, el inciso b) expresamente alude a la legislación nacional de cada Estado parte, lo que puede habilitar en este caso la interpretación que se hace del art. 120 CN (la Constitución es la ley de leyes de un país), en paralelo con los derechos que el orden jurídico reconoce en cada sujeto -incisos a, b y c-, a partir de ciertas premisas valorativas -principios de igualdad, de régimen democrático, etc.-.

En síntesis, es mentira la teoría que reza que los jueces al hacer su tarea, como así también cualquier intérprete, resuelven temas tan delicados (p. ej. establecer una "política" -no el sentido de política partidaria, desde luego- de la pena) a partir de premisas meramente lógicas. ${ }^{19} \mathrm{El}$ derecho no se juega en los laboratorios, ni es imparcial, ni puede ser reconducido a las ciencias naturales. Esta última visión trajo consecuencias nefastas en materia de dictaduras o de explotaciones encubiertas al servicio de desigualdades. El derecho es político. Está ligado a un conjunto de principios morales que sostienen y fundamentan, en última instancia, el orden jurídico de una comunidad.

La teoría que se propugna en este trabajo pretende servir, además, para clarificar un tema muchas veces descuidado. Las razones en general, y ante cada proceso en particular, por las que el Estado, a través de sus diferentes órganos, pone en funcionamiento el sistema penal contra un individuo. Mejorar las ideas expuestas sobre la teoría de la pena a partir de nuestra Constitución debe servir para analizar si se dan esos presupuestos a la hora de solicitar en concreto una sanción penal. En la medida que promueva el debate, este escrito habrá cumplido su finalidad.

${ }^{19}$ Véase al respecto Bacqué, Jorge A. \& Nino, Carlos S. (2008), "Fundamentos de derecho penal”. En: Lesiones y retórica. El problema de la ciencia del derecho y la ideología jurídica a propósito de las lesiones simultáneamente calificadas y atenuadas en los escritos de Carlos $S$. Nino, Vol. III, Gedisa, Buenos Aires. 